\title{
Chapter 7 \\ Nuclear Weapons, International Security, and Non-proliferation in the 2020s
}

\author{
C. S. Eliot Kang
}

Thank you for having me here in Rome to address nuclear weapons, nonproliferation, and the broader security environment. I would like to focus my remarks on our new initiative to launch a structured international dialogue on Creating an Environment for Nuclear Disarmament, or CEND. This is a topic of great interest to my boss, Assistant Secretary Chris Ford, who is unable to be here today. He sends his regrets.

Before I outline the CEND initiative, I would like to put it into context. This initiative emerged from the review process for the Nuclear Non-proliferation Treaty, or NPT. March 5 will mark the 50th anniversary of the NPT's entry into force, and the tenth NPT Review Conference will take place next April to May. These milestones are an opportunity to recall how the NPT has made the world safer and more prosperous. It is difficult to imagine how the world might have evolved without the NPT, how many states might now possess nuclear weapons, and how much more fraught it might be to pursue the peaceful uses of nuclear energy, science, and technology. This anniversary is also an opportunity for states to reaffirm their commitments to the Treaty, and to rededicate themselves to preserve and strengthen the nuclear nonproliferation regime for future generations.

NPT Review Conferences take place every five years. They are often quite contentious and feature sharp divisions among various groups of states, in particular over nuclear disarmament. You could be forgiven if you had the mistaken impression of a treaty in crisis. But you would be mistaken to focus on these divisions and ignore how much the NPT actually represents the common interests and aspirations of all of its Parties. All NPT Parties - nuclear-weapon states and non-nuclear-weapon states alike-are made more secure by an effective nonproliferation regime that prevents the further spread of nuclear weapons. The assurances provided by that regime facilitate peaceful nuclear cooperation and help create a security environment conducive to progress on nuclear disarmament. Nonproliferation, disarmament, and peaceful

\section{S. Eliot Kang $(\varangle)$}

US Department of State, Washington, DC, USA

e-mail: morrellts@state.gov 
uses of nuclear energy are not competing interests but shared benefits for all NPT Parties.

The past 50 years have seen significant progress on nuclear disarmament. The United States has reduced its total stockpile of nuclear warheads by approximately 88\% from its Cold War peak, from 31,255 nuclear weapons in 1967 to 3822 as of 2017. Many categories of nuclear weapons have been removed from our stockpile altogether. However, the dramatic reductions in nuclear arsenals that took place when Cold War tensions eased have largely run their course, and security conditions have become much less favorable. The long list of challenges includes long-running regional tensions in South Asia, the Middle East, and elsewhere. Some nuclear-armed states are modernizing and expanding their nuclear capabilities at the same time they are becoming increasingly assertive in challenging the existing international order.

The CEND initiative grew out of an effort to think creatively but realistically about how to move forward on nuclear disarmament in light of these challenges. It seeks to establish a dialogue on how all states can work together to create an environment conducive to further progress on nuclear disarmament. The CEND Working Group (CEWG) met in Washington, DC, July 2-3. Its primary goals were: first, to identify a list of challenges that would need to be overcome or questions that would need to be answered in order to create an environment more conducive to progress on nuclear disarmament; second, to establish and define an initial mandate for subgroups to examine those factors and questions; and third, to determine subgroup composition including co-chairs.

Non-governmental expert facilitators from the Carnegie Endowment for International Peace, King's College London, and the Clingendael Institute guided breakout sessions focusing on three themes. The first theme was reducing perceived incentives for states to retain, acquire, or increase their holdings of nuclear weapons. Participants decided to broaden the topic to address the converse: increasing incentives to reduce and eliminate nuclear weapons. The second theme was multilateral and other types of institutions and processes to bolster nonproliferation efforts and build confidence in, and further advance, nuclear disarmament. The third theme was interim measures to address risks associated with nuclear weapons and to reduce the likelihood of war among nuclear-armed states.

Over the course of the two-day conference, the NGO facilitators worked with each of the breakout sessions to identify areas of convergence for further work by subgroups. These areas of convergence were based on the observations of the facilitators and not necessarily the consensus views of the participating governments. To enable an open dialogue, it was necessary to limit the number of countries participating in the initial CEWG meeting, but in order for this effort to be taken seriously, we brought together an ideologically and geographically diverse group of countries to form the core group of CEWG participants. We achieved this, with participants hailing from 42 countries across the globe and representing governments that are both likeminded with our positions, as well as those with whom we have significant differences. All five NPT nuclear-weapon states - the P5-took part in this meeting, including my fellow panelist Vladimir Leontiyev. 
While the CEND initiative was motivated by a desire so stimulate a more realistic approach to disarmament in NPT-based deliberations, it has implications beyond the NPT. In addition to the P5-the NPT nuclear-weapon states-India, Pakistan and Israel, which are not NPT Parties, were active participants in the first meeting. For too long, the international disarmament discourse has focused almost exclusively on the P5. This ignores the obvious fact that even if the P5 eliminated all their weapons, the result would not be a nuclear weapon-free world. If we are to take the issue of nuclear disarmament seriously, then we need to involve states outside the NPT as well, for these states are located in regions where some of the most intractable obstacles to disarmament lie.

Every country has a stake in the dialogue around nuclear disarmament. CEND's success depends upon the active engagement of countries participating directly in the CEWG and helpful input from those not directly participating. We continue to encourage consultations by CEWG participants with other states in their respective regions. In particular, we have consulted with NATO Allies in Brussels before and after the first CEWG meeting.

Within the CEWG, deliberations took place under the Chatham House rule. Participants are free to discuss views expressed during the meeting, but should not attribute them to a particular speaker or country. And the views expressed do not necessarily coincide with those of the United States. With that in mind, I would like to simply list some of the areas of convergence within each of the topical subgroups.

The first subgroup addressed "reducing perceived incentives for states to retain, acquire, or increase their holdings of nuclear weapons and increasing incentives to reduce and eliminate nuclear weapons". It identified the following potential areas for further work:

- Articulate threat perceptions of states in regional (or global) competitions involving nuclear weapons more clearly and deeply so they can be better understood and addressed,

- Buttress existing arms control, nonproliferation and security mechanisms and compliance with them,

- Assess differing perceptions of the purpose of declaratory policy, including for deterrence and reassuring those most alarmed about the prospect of nuclear war,

- Improve capabilities and protocols to verify nuclear disarmament and

- Address the tensions between nuclear deterrence and concerns over the humanitarian consequences of nuclear war.

The second subgroup addressed "multilateral and other types of institutions and processes to bolster nonproliferation efforts and build confidence in, and further advance, nuclear disarmament". The following areas of convergence for further work emerged:

- Strengthen and maintain existing institutions through preserving what we have, maintaining the disarmament architecture, and avoiding politicization of existing institutions and agreements, 
- Strengthen and reaffirm commitment to the NPT by monitoring progress with existing commitments and acknowledging the NPT is the "cornerstone" of the global nonproliferation and disarmament architecture, and

- Develop a list of practical measures with a view to improving the security environment through focusing on nonproliferation measures, building trust and confidence, and identifying what is practical now.

The third subgroup considered "interim measures to address risks associated with nuclear weapons and to reduce the likelihood of war among nuclear-armed states, and found the following areas of convergence:

- Reduce the likelihood of nuclear weapon use through conflict management and prevention,

- Build trust through transparency and confidence building measures in the area of risk reduction, and

- Improve communication and dialogue among states possessing nuclear weapons and between states possessing and not possessing nuclear weapons.

We are now turning to next steps, including convening a second CEWG meeting, which will take place November 20-22 at Wilton Park in the UK, by invitation only. All three subgroups will meet. This will allow for greater cross-pollination between subgroup discussions and should also allow participating countries to cover all three subgroups with one or two representatives. Subgroup co-chairs will play an important role in making this and subsequent meetings successful. The Netherlands is co-chairing the "reducing incentives" subgroup, with the other co-chair still to be confirmed. South Korea and the United States will co-chair the "nonproliferation institutions" subgroup. And Germany and Finland will co-chair the "risk reduction" subgroup.

We are also working to enlist NGO support as part of a consortium approach. NGOs would provide needed resources to the CEWG process, including by assisting the co-chairs and by facilitating discussions, but the substantive discussions will continue to take place only among government delegations.

Before I close, allow me to say a few final words about the goals of the CEND initiative in the NPT context. By the 2020 NPT Review Conference, subgroups will have met in person at least once more, with associated intercessional work being conducted between meetings. We do not plan for the CEWG to have completed a "phase" of its work before the RevCon, as that is an unrealistic timeline for the CEWG to have developed finished deliverables for the serious and difficult work it is tasked with. However, by the RevCon, CEWG subgroups will have clearly outlined their plans of work. At the RevCon, the CEWG subgroup co-chairs will be able to present a clear plan for progress that will continue past the 2020 RevCon. We envision holding a side event to lay out these plans.

In closing, I want to emphasize two key points. First, the US government fully supports this initiative. But second, we have no intention to micromanage its proceedings or prejudge its outcomes. We received uniformly positive feedback from 
our first meeting, thanking us for the deep, substantive interactions of our first meetings, which allowed participants to get past their standard talking points and develop a real understanding of each other's perspectives. We aim to build on that foundation. Ultimately, it is up to the participants to determine the direction that these dialogues take.

Open Access This chapter is licensed under the terms of the Creative Commons Attribution 4.0 International License (http://creativecommons.org/licenses/by/4.0/), which permits use, sharing, adaptation, distribution and reproduction in any medium or format, as long as you give appropriate credit to the original author(s) and the source, provide a link to the Creative Commons license and indicate if changes were made.

The images or other third party material in this chapter are included in the chapter's Creative Commons license, unless indicated otherwise in a credit line to the material. If material is not included in the chapter's Creative Commons license and your intended use is not permitted by statutory regulation or exceeds the permitted use, you will need to obtain permission directly from the copyright holder. 